\title{
Urgences
}

\section{Comme la chambre claire}

\section{Marie Bélisle}

Numéro 27, mars 1990

Images imaginaires

URI : https://id.erudit.org/iderudit/025568ar

DOI : https://doi.org/10.7202/025568ar

Aller au sommaire du numéro

Éditeur(s)

Urgences

ISSN

0226-9554 (imprimé)

1927-3924 (numérique)

Découvrir la revue

Citer ce document

Bélisle, M. (1990). Comme la chambre claire. Urgences, (27), 21-27.

https://doi.org/10.7202/025568ar d'utilisation que vous pouvez consulter en ligne.

https://apropos.erudit.org/fr/usagers/politique-dutilisation/ 


\title{
Comme la chambre claire
}

\section{Marie Bélisle}

\author{
.0. \\ je t'approche je te frôle \\ le sais-tu \\ tu me touches je le vois \\ je te mords je te prends \\ le sais-tu \\ tu me pénètres je le vois
}

la photographie (impossible):

Ils seraient vêtus, noir, blanc; ils se feraient face, l'un et l'autre alternativement immobiles dans l'illusion de l'image, fixés par le grain même caché de la peau comme du papier;

elle l'approcherait; elle le frôlerait; il la toucherait; d'un moment à l'autre, comme dans une insoutenable légèreté, ils seraient (re)pris l'un par l'autre, pénétrés par le mouvement itératif du désir; le savez-vous.

\section{la chambre:}

Ils seraient nus, d'abord face à face, mobiles tous les deux dans l'effet de réel, saisis par la lumière beige de leur peau;

leurs profils s'approcheraient; ils se frôleraient; ils se toucheraient; d'un moment à l'autre, comme dans un glissement progressif, ils seraient pris l'un par l'autre, pénétrés par le mouvement continu de la séduction; nous les voyons. 
ainsi fixée par la lenteur absentée je t'approche

le sais-tu

\section{l'impossible photographie:}

Ainsi fixée par la lenteur du mouvement, comme absentée de son propre geste, elle se lève de la chaise, fait un pas en avant, puis un autre pas en avant. Ainsi, lentement, s'approche-t-elle du personnage de l'impossible photographie. A la fin son image, de dos, recouvre presque entièrement, cache le personnage de l'impossible photographie désormais comme absenté de l'image, seuls demeurant de lui ses cheveux retombés sur le front par conséquent.

\section{la chambre:}

Il ne bouge pas; il respire, comme appuyé à la lisière gauche de l'image. Elle se détache de la lisière opposée.

Elle l'approche. Il ne la regarde pas venir. Sa tête est penchée en avant, ses cheveux retombés sur le front par conséquent. Il sait qu'elle vient. 


$$
\begin{gathered}
\text { 2. } \\
\text { impressionnée même par la lentille } \\
\text { embrasée } \\
\text { je te frôle } \\
\text { le sais-tu }
\end{gathered}
$$

l'impossible photographie:

Impressionnée même par cette lentille qui la fixe, elle se lève de la chaise, fait un ou deux pas jusqu'à toucher de tout son corps le personnage de l'impossible photographie; elle le frôle, elle se frotte à lui. Puis elle se retourne lentement. C'est son épaule, son bras, puis sa main seulement qui frôlent le personnage de l'impossible photographie. À la fin son image de face laisse voir, décalée, l'image du personnage de l'impossible photographie. Elle se sait embrasée.

\section{la chambre:}

Il respire, appuyé à la lisière gauche de l'image. Il relève lentement la tête. Elle continue d'approcher jusqu'à ce que sa poitrine touche celle de l'homme qu'elle frôle, des seins, de l'épaule, du bras, de la main, en pivotant jusqu'à lui offrir son profil droit. Il la sait embrasée. 
24

.3.

caché exactement par le champ

immobile

tu me touches

je le vois

la photographie:

Caché en partie par le champ exactement immobile, de moins en moins caché cependant il avance vers (le personnage de) la photographie exactement immobile. Lentement il allonge le bras la main vers elle. Sa main se pose. Il la touche. Sa main passe sur la surface satinée du papier, cachant un instant les yeux du personnage de la photographie exactement.

\section{la chambre:}

Il bouge. Son bras droit, sa main s'élève lentement vers elle. sa main se pose. Il la touche. Sa main passe sur la surface satinée de la peau entre les seins et le cou. Sa main remonte vers le visage. Il touche ses yeux, elle le voit. Puis elle les ferme, sous la main de l'homme exactement. 


$$
\begin{gathered}
.4 . \\
\text { objectivement révélée par la lumière } \\
\text { innommée } \\
\text { je te mords } \\
\text { le sais-tu }
\end{gathered}
$$

l'impossible photographie:

Objectivement innommée, encore elle se lève de la chaise, avance vers le personnage de l'impossible photographie. Elle l'atteint de tout son corps. De très très près le cou offert du personnage de l'impossible photographie l'appelle.

Elle approche ses lèvres, les ouvre. Elle écarte légèrement les dents, les pose puis les referme. Elle le mord précisément en cette zone de la peau révélée par la lumière.

\section{la chambre:}

La main de l'homme ne bouge pas. La femme se retourne vers lui. Les doigts de l'homme passent dans les cheveux de la femme par conséquent. Face à lui, très très près de son cou, elle approche les lèvres de la peau de l'homme, les ouvre, pose ses dents entrouvertes. Il sait qu'elle le mord précisément en cette zone claire de la peau révélée par la lumière. 
26

5.

séduite tellement par la luxure obstinée

je te prends

le sais-tu

l'impossible photographie:

Séduite tellement par le personnage de l'impossible photographie, elle se lève de la chaise, avance vers lui.

(E)mue par la luxure insinuée dans l'immobile, elle colle son corps à celui du personnage de l'impossible photographie.

Elle lève ses bras vers lui, elle l'entoure, elle le prend.

Elle l'étreint, obstinée. Les cheveux du personnage de

l'impossible photographie retombés sur son front par conséquent effleurent son épaule à elle.

\section{la chambre:}

La main de l'homme est maintenant sur la nuque de la femme. Elle ne le mord plus : elle le baise. Elle lève ses bras vers lui. Elle l'entoure, elle le prend. Ses mains bougent sur le corps de l'homme. Il sait qu'elles cherchent son sexe. Elle l'étreint. La tête de l'homme est penchée, ses cheveux par conséquent effleurent l'épaule de la femme. 
.6.

instantanément renversant le charme

obscur

tu me pénètres

je le vois

\section{la photographie:}

Instantanément il s'avance vers (le personnage de) la photographie. Il s'avance jusqu'à la toucher. De tout son corps, il touche (le personnage de) la photographie. Elle ne résiste pas. De tout son corps il la pénètre. renversant le charme il la pénètre. Il traverse l'image. À la fin, de dos, il s'immobilise obscur derrière (le personnage de) la photographie.

\section{la chambre:}

Il ne bouge presque pas. Appuyé à la lisière gauche de l'image, il tient le corps de la femme collé au sien.

Elle renverse son bassin. Son dos bascule vers l'arrière. Les paumes de l'homme sont sur ses reins maintenant, la maintiennent. Les hanches de la femme bougent.

Il la pénètre, elle le voit. Puis ils s'immobilisent, clairs dans la jouissance, obscure. 